\title{
OPEN
}

\section{6 \\ Against Reciprocity: Dynamics of Power in Interdisciplinary Spaces}

Abstract: All too often, 'reciprocity' emerges as the (imagined) organizing logic of interdisciplinary collaboration - with collaborators invited to forms of mutuality, fair exchange, and so on. In this chapter, we show what is missing from this analysis, which is any account of power. The chapter thus takes up an analysis of how power works in an interdisciplinary space - setting out, in particular, some of the different financial, epistemic, and cultural resources that belong to different disciplines. But if the chapter sets itself against one fantasy (fair exchange), it also wants to dispel another - and this is the fantasy of power confronted by the frankly-spoken truth. The chapter argues instead for what it might mean to think interdisciplinary collaboration as a practice of subjugation, which different collaborators may just have to learn to live with.

Keywords: collaboration; interdisciplinarity; power; subjugation; trading zones

Callard, Felicity and Des Fitzgerald. Rethinking Interdisciplinarity across the Social Sciences and Neurosciences. Basingstoke: Palgrave Macmillan, 2015. DOI: $10.1057 / 9781137407962.0009$. 


\section{Introduction}

The familiar register of exhortations to interdisciplinarity - mutuality! reciprocity! exchange! - is one that assumes that differentials of power do not exist. And yet, for many people from the humanities and social sciences - and we are thinking quite beyond our own collaborations here - experiencing one's role in a collaboration with life scientists as a relatively powerless one undercuts these kinds of exhortations. Go to the bar at any science and technology studies conference, and it won't take too many drinks before social scientists start telling you about how their research is often understood as 'public engagement'; how they consistently have to justify their expertise to their collaborators; how they have to translate (or sometimes give up on) their conceptual language in a way that is not always reciprocated, and so on. This doesn't mean that life scientists in collaborations are especially power-hungry; or that they behave badly (no doubt most would be surprised and taken aback to learn that their collaborators would narrate their experience in such ways). But it is to say that when a group of people collaborate within institutional structures that end up placing the more highly valued epistemological frameworks, as well as financial resources, largely on one side, then asymmetries result.

Even among - and perhaps especially among - the most well-meaning people, such asymmetries can produce some unlovely relations. It is important to note that such relations are rarely, if ever, explicitly endorsed by collaborating life scientists, and life scientists themselves often do not gain from them. Indeed, to the extent that interdisciplinary asymmetries of power can produce silences and absences, there is a significant risk that they reduce the space for the complex collaborative entanglements that motivate many scientific collaborators in the first place. Perhaps more importantly, and this is perhaps not always so visible to collaborators, even if natural scientists in particular collaborations may appear to hold all the power, those scientists themselves are subject to precisely the same asymmetries, when they reenter a larger prestige economy that might mark their collaborations with social scientists or humanities scholars as decidedly low-value contributions. And this is to say nothing of the way that natural scientists may experience a more subtle asymmetry, as they get pinioned by the philosopher's or literary theorist's rhetorical monopoly on, and their own explicit exclusion from, what it means to think 'critically'. (Indeed, we have lost track of the number of times we 
have heard humanities scholars and interpretive social scientists lament the naivety of scientists for having the temerity to proceed as if the world were real, or for going ahead with experiments that are patently 'reductionistic' of the phenomena they are studying, as though the scientists haven't thought long and hard about which kinds of reduction might be most potent in the particular experimental situation in which they find themselves.) It is true that we are two social scientists who have, at times, found ourselves on the wrong end of such relations, and we will not deny that this chapter is significantly motivated by our own desires to understand and think those relations as we have felt them. Still, even as we emphasize the partiality of our account, we insist that such an interpretive labour is vital for the collaborating natural scientist too.

In what follows, then, we think through relations of power in interdisciplinary research projects that bring the biosciences and the social sciences into intimacy with one another. We will be concerned not so much with providing a rich sociological account of how power operates in collaborative projects, but, rather, with the ways in which significantly interdisciplinary research in those spaces is produced through structures of power that position different people, and objects, and ideas, in very specific ways. At the heart of the chapter is an attempt to show that interdisciplinarity is entangled in much thicker structures of power than either its promoters or its practitioners are willing to recognize. We hope that that it is clear, already, that what follows is not a screed about the fantastic power of neuroscience. (Nor do we want to be misread as wilfully ignoring the multiple and diverse instances of generosity, and laborious work on our behalf, that our collaborators have shown towards us.) Even as we work through our own, often fraught, relationship with what we experience as collaborative asymmetry (and we have only this to work through), the chapter remains motivated by a distinctly ambivalent relationship both to how power operates (we do not describe, here, a simple pinioning of one 'side' by another), and to what it might make possible. This final point guides the second half of the chapter: here, we are going to claim that interdisciplinary collaborators need to give up not only the official fantasy of 'mutuality', but also on that fantasy's self-consciously critical mirror-image, viz. the idea that relations of power need either to be overcome or at least faced up to through reinvigorated forms of transparent dialogue, mutual respect, frank talking, and manifestations of emotions appropriate to the situation, such as anger (e.g. see Rabinow 2009). In what follows, we are going to reach towards a less comfortable 
conclusion: oftentimes, we suggest, the labour of collaboration is less a task of learning to speak up for yourself - in the service, say, of 'achieving a more just recognition [for one's] substantial efforts and contributions' as social scientists or humanities scholars (Rabinow 2009, 318) - and rather more a labour of adjusting to, precariously acquiescing to, and, on occasion, becoming curiously attached to, states of subjugation.

We offer one final disclaimer before proceeding: at least since the work of Michel Foucault (e.g. Foucault 1982), and probably indeed going back to the writing of Max Weber (see e.g. Wallimann, Tatsis, and Zito 1977), power has been a central concept - one might say a 'master concept' - of the interpretive social sciences (as well as significant parts of the humanities). When we talk about power in this chapter, we commonly use it in the more commonsensical Weberian sense (i.e. as the ability 'to secure one's own ends' in a social relationship (Wallimann, Tatsis, and Zito 1977, 231)). But occasionally, too, we invoke the term in Foucault's sense (i.e. as a technique that 'categorizes the individual, marks him by his own individuality ... [and] imposes a law of truth on him which he must recognize' (Foucault 1982, 781)). The chapter is undoubtedly inflected, too, by other theoretical and philosophical interventions on power and subjugation that work to understand how it is that 'the subject is the kind of being who can be exploited, who is, by virtue of its own formation, vulnerable to subjugation' (Butler 1997, 20). Again: we are indebted to accounts of subjecthood and to relationality in which exposure to and entanglement with power is a deeply ambivalent process, one in which what is unbearable can also be the site of hope and strange attachments (see e.g. Berlant and Edelman 2014).

Such theoretical armature is, probably, of little concern to those readers more preoccupied with our accounts of what it's like to live in these interdisciplinary spaces. We mention these lineages, however, to alert those who are interested to the fact that we have thought long and hard about subjugation both inside and outside the interdisciplinary settings that are our specific focus here. We want to forestall a response that we commonly receive to our invocations of subjugation, viz. being lambasted for our political pusillanimity and/or for our unhappy turning away from 'the demands of the day' (e.g. Stavrianakis et al. 2014). By claiming a space for subjugation, we are neither jettisoning the importance of anger, nor the need to acknowledge that social relations of collaboration are, on occasion, intolerable and irreparable. But we contest a logic in which social scientists and humanities scholars should, in the face of 
such relations, remain tethered to a fantasied longing for recognition, or for an endorsement of their own value within those collaborations.

\section{Mutual intellectual and professional respect}

Rhetorics of reciprocation and mutuality suffuse the 'grey' literature on interdisciplinarity. Here, for example, is the description of an interdisciplinary funding programme, 'Science in Culture', run by the UK's Arts and Humanities Research Council (AHRC): the Science in Culture theme 'aims to develop the reciprocal relationship between the sciences on the one hand, and arts and humanities on the other'; through such reciprocal relationships, the theme will 'encourage mutual exchanges between the sciences and the arts and humanities that offer scope for developing new areas of research, methodologies, research frameworks styles of thinking and/or ways of working across the disciplines' (Arts \& Humanities Research Council 2015). Or consider this promotional material for a conference on interdisciplinarity at Durham University: 'By exchanging knowledges interdisciplinary collaboration has the potential to generate new thinking and transform the way that participants think about their own work. This can be tremendously exciting and rewarding' (Durham University n.d.). Or take this statement from the 'Vilnius Declaration' on the role of the social sciences and humanities ('SSH') in the European Union's Horizon 2020 research funding programme:

Solving the most pressing societal challenges requires the appropriate inclusion of SSH. This can only succeed on a basis of mutual intellectual and professional respect and in genuine partnership. Efficient integration will require novel ways of defining research problems, aligned with an appropriate array of interdisciplinary methods and theoretical approaches. SSH approaches continue to foster practical applications that enhance the effectiveness of technical solutions. (Mayer, König, and Nowotny 2013, 26)

Integration. Mutuality. Reciprocation. Rewarding exchange. Shared solutions. Such is the terminology through which both the bureaucratic and intellectual imaginaries of interdisciplinary research take shape. There is a very particular idea of interdisciplinary exchange embedded in this language: one in which actors from different disciplines, if they are not exactly (or not quite yet) trading and exchanging their knowledge in settings characterized by mutual respect and reciprocation, then at least 
this is something they're aiming for. As the organizers of the Vilnius conference (the event that produced the 'Vilnius Declaration', cited above) put it:

the SSH community should be alerted to reflect on how to deal more actively with the opportunities that the shifting framework conditions of Horizon 2020 offer to them, instead of complaining about losing their stakes..... Only through a mutual and open discussion how to shape and practically apply the 'integrative approach' could [this conference] be made to work in earnest. (Mayer, König, and Nowotny 2013, 16)

But there is surely more going on, here, than the optimism we might see undergirding this desire. The Vilnius Conference was organized precisely because the European Union, in putting together its eighth Framework Programme for research funding, favoured an 'integrative' interdisciplinary approach, which many saw as a diminution of the role of the social sciences and humanities. In other words, the conference came at the foot of a series of 'interdisciplinary' developments that served very precisely to demonstrate how marginal these disciplines sometimes are to the intentions of powerful actors. And yet still the hope - of a 'mutual and open discussion' - remains.

\section{Fantasies of power}

What is little mentioned across these bureaucratic and public-facing formulations is how interdisciplinary collaborations are structured through very different adjudications of epistemic authority (but see the contribution of Ulrike Felt in Mayer, Konig, and Nowotny 2013, 57) - or that, within and beyond particular projects, different actors have access to very different pots of money; that their practices of writing are differently legible, that they are differentially supported by governments and private foundations; that their views carry differential weights within policy communities, and so on.

Things look a little different if one turns to the scholarly literature. In an analysis of an emergent interdisciplinary field crossing economics and geography, for example, geographer Erica Schoenberger worries about how historically nuanced concepts and methods that are central to her own discipline are disregarded in a 'disciplinary imperialism': the new endeavour 'exclude[s] social conflict and power relations, which are both 
mathematically and ideologically inconvenient...geography has been excised from an activity that nonetheless calls itself the new economic geography' (Schoenberger 2001, 378). And it is forms of 'social power' which is to say, in this case, powerful institutions (Harvard and MIT) and disciplines (economics) - that make the difference. Sharachchandra Lélé and Richard Norgaard, drawing on their work in interdisciplinary climate-change projects, put the situation even more starkly: 'there are', they point out, 'significant differences in the manner in which society treats the social and natural sciences... Naturally, the social sciences are seen as irrelevant, boring, and nonrigorous .... They go on:

the social scientists, because they purportedly were not good enough to get into the 'science stream', are often in awe of the natural sciences. The belief of the superiority of the natural scientists is so deep-rooted that whenever social problems have the slightest technical dimension, politicians have traditionally called on only technicians - the natural scientists - to help solve them. (Lélé and Norgaard 2005, 971-972)

Not only do social scientists get side-lined in such projects, on Lélé and Norgaard's account, but natural scientists are asked to fill the breach: 'Charged with providing policy recommendations, [natural scientists] have to make judgments about how society works. They do not have adequate training to do this, but they are perhaps emboldened to do so by their position and are likely to adopt simplistic models of social dynamics' (Lélé and Norgaard 2005, 970).

In one empirical analysis of an interdisciplinary sustainability project, Susan Gardner shows how attention to status and hierarchy ran through the project - with her social science interlocutors giving their answers through 'nervous laughter' versus what Gradner describes as the more self-confident responses of the natural scientists. 'I have some difficulty seeing some of the value of some of the social sciences', one of the natural scientists tells Gardner: 'I have sat through a number of lectures that some of the social science people have given and walked away wondering what the point was' (Gardner 2012, 248). Another tells Gardener that the social scientists on the project are pretty 'squishy' - " "Where were the hypotheses? How much data were gathered? Where are the statistics?" (Gardner 2012, 248).

To be sure, this is a one-sided account: even if it is not obvious in the literature we have presented above, we have no difficulty in believing (indeed, are assured by our scientist collaborators that it is the case) 
that collaborating life scientists, too, experience such asymmetries. This occurs both within individual collaborations (one can well imagine the humanist's equivalent of 'Where were the hypotheses?') and beyond them: to collaborate with people who might be a bit 'squishy', after all, is unlikely to represent much a grab for the garlands and esteem of your scientific peers. But rather than cataloguing this back and forth, what we want to do here is undercut the fantasy that might follow on from both sets of complaints. This is the fantasy of power confronted. For Lélé and Norgaard, for example, the key to high-quality interdisciplinary practice is researchers throwing into question the barriers that generate these biases: 'contrary to their disciplinary training', they argue,

participants [in interdisciplinary projects] need to be self-reflective about the value judgments embedded in their choice of variables and models, willing to give respect to and also learn more about the 'other', and able to work with new models and taxonomies used by others. (Lélé and Norgaard 2005, 975)

For Schoenberger, geography should revert to its own internal interdisciplinarity (here geography is in a relatively unusual position, we would say), or it could go looking for more interesting economists to talk to (Schoenberger 2001, 379-380). For Bronislaw Szerszynski and Maialen Galarraga, who are especially interested in the case of geo-engineering, the task of social scientists in these situations is to 'expose assumptions, bring out the multiplicity and incommensurability of different views and ontologies, and keep problem definitions open' - thus producing 'greater diversity and reflexivity in how different disciplines and approaches are brought together' (Szerszynski and Galarraga 2013, 2818, 2822). For Dena MacMynowski, clear differentiation is the key to good synthesis: in order for interdisciplinary research to proceed more transparently in terms of the recombination of ideas and making the power associated with knowledge claims explicit, interdisciplinary environmental research needs to consciously embark on a process of differentiation and clarification before, or while, moving toward synthesis' (MacMynowski 2007).

From many years thinking about and living in interdisciplinary spaces, we have learnt that this account of power confronted - in which differentials are acknowledged and addressed, and even occasionally overcome; or in which, at least, a model of interdisciplinarity less riven by relations of power is thought to be imaginable - is no less fantastical than the dream of mutuality with which we began. You can have all the frank conversations in the world with collaborators about the conditions 
under which your exchanges are taking place; you can agree on a clear distribution of resources and labour throughout the collaboration; you can put in agreed strategies to ensure, as far as possible, that this will work; you can remain as open, and transparent, and clear, and dialogic as possible; but the reality is that financial and epistemic power is not distributed equally within the collaboration. That irrevocable state of affairs carries many sequelae in its trail. And everyone in the collaboration, in her heart of hearts, knows this.

\section{After reciprocity}

What is it, then, that is desired in subjection? Is it a simple love of the shackles, or is there a more complex scenario at work? (Butler 1997, 27)

What would happen if we gave up on mutuality altogether? What if we abandoned the ideal of 'reciprocity'- not because it isn't realistic, but because it may not actually be desirable? Lately, and instead of adding our own analysis of how 'exchanges' might take place in interdisciplinary spaces, we have begun to wonder if new conceptualizations of interdisciplinarity would come into view if this term were not subject to the velvet stranglehold of mutuality. All of us who have collaborated, after all, have experience of doing so without any expectation either that everyone is on the same footing, or that meaningful forms of process, dialogue, and so on, will actually produce parity. So what if we just accepted, in the most basic sense, that if you're a humanities or social science person in an interdisciplinary neuroscientific project, then there is some likelihood that you're going to have to meet your interlocutors more than halfway, that the emotional labour of holding things together might well fall substantially to you, and that there's a good chance that you're going to have to take responsibility for much of the project 'housework'? What if, as a natural science person, you made peace with the fact that your collaborators will assume you have never thought through your field's problematic use of particular terms, that they will sometimes treat you as a kind of veil of rigour, granting them access to various pots of money, and then expect you, as one of the few scientists who can be bothered to attend 'interdisciplinary' meetings, to consistently represent all that is 'wrong' with your discipline? 
These are, we are quite aware, not the happiest of counsels. But the point we make in this chapter is three-fold. First, the advice consistently given to would-be collaborators - Make your goals clear! Know what your expertise is! Begin a frank dialogue! - bears no relationship to our and, we think, our collaborators' many experiences of working in interdisciplinary projects, and of making space for our own interests within forms of financial, epistemic, and bureaucratic power that consistently produce those interests as contingent on the scientific questions in which they are entangled. Our natural scientist colleagues, similarly, will tell you many stories of their research interests being figured as inherently crude, reductive, and simplistic - of being imagined as dependent on the nuances of the cultural-historical questions that bear down upon them, in their turn. If you are going to live in such spaces, better to learn to live in them as they are, and give up on an agentic fantasy in which you will be able substantively to transform imbalances, inequalities, and existing norms governing epistemic (and other kinds of) potency.

Second, as two social scientists caught in this space, we have learnt neither to lament, nor to spend energy resisting, this state of affairs: what we have learnt, instead, is sometimes to subjugate (or at least accept the subjugation of) our work and our interests to the neuroscientific interests in which we seek to entangle them. To the extent that we, in order for our research interests to move forward, need 'the neuroscientists', and they can get on perfectly well without us (in our estimation, anyway), we remain intensely aware that we need to narrate our own research interests in ways that make sense to our collaborators, without much expectation that they will do likewise. If we often know more about cognitive neuroscience than any of our collaborators do about geography, sociology, the history of science, and so on - this is not because we find ourselves diligent, but because we find ourselves weak. (Again, we speak only from the social science perspective here; no doubt there is a mirror image of this point, from the point of view of neuroscientific collaborators, which we will not presume to ventriloquize.)

Third, what we are trying to emphasize here is that a good enough politics of collaboration is not, in fact, exhausted by exhortations to frank speech and/or by demanding the recognition of one's epistemic and other contributions. One of the most important lessons we have learnt from our interdisciplinary work since 2008 (see especially Fitzgerald et al. 2014a) is that parity is overrated as a platform for exchange - that is, the fantasy of two more-or-less equal actors, exchanging their intellectual 
goods in a spirit of reciprocal esteem, might not only be, in a basic sense, and like most fantasies, not 'true', but that it might also be more politically and epistemologically inert than has often been assumed. Because what this prim fantasy excises is any sense of risk and play - any sense of the intensity of a pleasure that might come from giving one's self up to something and taking the consequences (see e.g. Dean 2009). Indeed, the sociologist Andrew Balmer, in taking up this theme of subjugation, has analysed interdisciplinary relationships through the dynamics of playful sadomasochism, insisting, with Michel Foucault, that such scenes are not simple exercises in domination, but that they enact 'way[s] of creatively playing with strategic power to constitute new pleasures, new modes for engagement with each other and with the world more generally' (Balmer 2013). Balmer thus reminds us that there are intensely affective ethical and political structures, as well as forms of action and pleasure, located in such relational practices - practices that are, we would add, quite invisible to genteel exhortations to dialogue.

\section{Interdisciplinarity and the reproduction of social power}

We have cast ourselves, at least a few times, in this chapter as marginalized subordinates within spaces of great epistemological privilege. As we have stressed, we do not remain unaware of the ways in which 'we', and our disciplinary and epistemological preoccupations, are undoubtedly variously irritating to and undermining of the scientific and emotional labours of our collaborators; we are aware that, even if we too often feel ourselves to be under the scientific thumb, there are in fact many kinds of power - institutional, epistemic, managerial - that we can and do wield in interdisciplinary settings. But here is yet another objection to how we have positioned ourselves in this chapter - and another route through which we want to turn simplistic accounts of interdisciplinary power on their heads. We both have many colleagues, in our own disciplines (and in other disciplines from the humanities and the interpretive social sciences), who would gently point out that, from their perspective, our state of subjugation (such as it is) quite clearly has arisen from our having gotten ourselves into some very problematic spaces; that not only is it specious for us to cast ourselves as subjects of power, but that, in lending our support to, and expanding the reach of, scientific disciplines 
(not least the neurosciences), we throw our lot in with those disciplines that we are, in other words, co-producers of the very epistemic power from which we claim to distance ourselves (Cooter 2011, 2014). Worse (we caricature here): the sciences with which we are entangled have been the source of deleterious discourses on, for example, race, class, and gender; that scholars in the social sciences and humanities had long built up a conceptual armature to counteract such discourses; and that by mingling those concepts with the methods and theories of the neurosciences, people like us actually evacuate the space for such critical work. To the extent that people become raced, gendered, and classed subjects through particular relations of power, and to the extent that scientific research has bolstered and solidified such relations (especially when it is increasingly licensed to talk about social life) - then our dirge for subjugation starts to look hollow indeed.

This is a vexed and serious critique that we cannot do justice to here. It is undeniably true that neuroscientific research has been mobilized in deeply problematic ways (we say 'mobilized' to gesture at the frequent distance between research in the laboratory and its diverse applications). There is now an extensive body of research on the effects of neuroscientific discourses on policy, especially as that policy has been brought to bear on predominantly working-class and ethnic minority families (e.g. Edwards, Gillies and Horsley 2015; Lee, Macvarish and Lowe 2014; Pykett 2015). There is an even more prominent discourse about neuroscience and gender, which is often self-consciously essentializing (e.g. BaronCohen 2003) - resulting in popular claims that are, as the psychologist Cordelia Fine has pointed out, sometimes 'spurious' or 'misinterpreted' (Fine 2010, 283). 'The imaginative reader', Fine goes on,

will not have too much difficulty envisaging how, by reinforcing stereotypes, such claims may affect people's social attitudes in ways that oppose progress toward greater gender equality, just as such claims did in the past. (Fine 2010, 283)

Against such invidious stereotypes, many will claim that the conceptual armature of the interpretive social sciences - culture, context, sociality, ideology, historical contingency, political decision-making, and so on - has helped to destabilize powerful scientific discourses, as they have been brought to bear (with or without the consent of their scientific progenitors) on many different kinds of people. This, many of our colleagues would remind us, is where the conversation about power in interdisciplinary neuroscience needs to be. 
And yet, at the heart of our different projects in this area, there has always been an intuition that a potent, (potentially) emancipatory politics of race, gender, class, or sexuality might not have to be always independent of the biological sciences. In pursing that intuition, we have been inspired, for example, by the work of the NeuroGenderings research collective, and by the potent forms of neurofeminism that many of the scholars within that loose agglomeration have insisted on locating at the heart of empirical brain research (Bluhm, Jacobson and Maibon 2012; Schmitz and Höppner 2014a, 2014b). We have learnt a great deal from scholars such as Gillian Einstein and Margrit Shildrick, who, in their reinvigoration of the politics of women's health, have always insisted on the complementarity of feminist theory and biological research on women's bodies (Einstein and Shildrick 2009). And we continue to be propelled by broader movements, within feminist theory, that are working to destabilize (to de-nature, we might say) the suturing of politics to critique, showing how feminist (and other social) theories might yet be traced through neurobiological histories and practices (Barad 2007; Rose and Abi-Rached 2013; Wilson 2004). If our own projects maintain a committed attention to the ways in which epistemic and cultural privileges can be put to work in the generation or sustenance of some deeply worrying relations of power, still, we have tried to show, in the empirical work that we have produced, that an interdisciplinary attention to brain and mind can also unsettle these relations in sometimes unexpected ways; that neuroimaging studies, themselves, can sometimes themselves be the bearers of critical practices.

\section{Learning to live together}

What are we to do, in the face of the unappetizing dynamics that have coursed through this chapter? One answer is: nothing. Donna Haraway, in her 'Companion Species Manifesto', surely the most compelling recent treatise on the complexity of relating through fraught boundaries, argues that 'all ethical relating is knit from the ... thread of on-going alertness to otherness-in-relation. We are not one, and being depends on getting on together' $(2003,50)$. Haraway's not-oneness, of course, is not a fantasy of always satisfied affiliation and exchange: humans' relationships with dogs are as filled with 'waste, cruelty, indifference, ignorance and loss', as much 
as they are about 'joy, invention, labor, intelligence, and play' (2003, 12). Rather than simply seeking to resolve such a tension, Haraway, instead, makes an intellectual and ethical commitment to understanding, thinking, and working with and through the polyvalent realities of multispecies relation - a commitment that she names elsewhere as 'staying with the trouble' (Haraway 2010) - that is, of continuing to work on and in a world that, in all its inter-species relatedness, is quite inseparable from complex intertwinements of killing, and breeding, and companioning, and nurturing.

We and our collaborators are not quite different species, nor have we yet started killing each other. Still, in understanding the often uncomfortable dynamics of our own collaborative relating, we want to take Donna Haraway's injunction to heart. We want, in other words, as interdisciplinary scholars, not to seek mythical platforms for equal exchange, but to keep learning different ways of being unsettled together. In this sense, we want to abjure the fleeting comforts of frank-speaking, and the self-limiting, self-satisfying pleasure of confronting power; we want to say, in their place, that we are, in fact, willing to stay with the trouble of learning to live together.

\section{Notes \& Queries: 6}

Q: In terms of inequalities, asymmetries, and lack of parity, where would you say the particular pressure points frequently lie? What should I be mindful of, if and when I enter interdisciplinary spaces?

A: While this is an important question, we should stress that we do not wish to paint interdisciplinary research as a kind of endlessly asymmetrical toiling - with the interdisciplinary researcher herself then only called upon either to manage, or live within, such unhappy relations of power. We do think that there is much more to be said about how power works in the interdisciplinary scene (certainly more than we have said here); more importantly, we want to suggest there is much to be gained from interdisciplinary collaborators at least becoming more alive to those dynamics, to how they work in their own right, but also to how they structure the emergence of the problem-space as such. To that end: there is a host of (usually) individually minor things that we (singly and together) have learnt to attend to, across a wide number of interdisciplinary 
collaborations - but which, systemized, and understood as an accumulation, may help to bring the power dynamics of a particular collaboration into understanding. We are not saying that these are inevitable - nor do they invariably position the social scientists and/or humanities people in the so-called 'weaker' position. And nor (though we have not at all paid enough attention to this dimension here) can they be abstracted from much thicker dynamics of race, class, and gender - which may not be visible on the surface of particular collaborations, but of course are significant determinants of the broader infrastructure from which those collaborations emerge (we need only think of the gendering of discipline at the university level, to see how such dynamics might become pertinent). An inexhaustive list of things to look out for would certainly include some of the following:

- Interdisciplinary research projects are made possible by a vital, and yet often undervalued and invisible, labour of 'housework' ranging from paperwork, to dealing with university and research administrations, to ensuring that everyone in the collaboration is okay, and so on. Who does this work, and what value is assigned to it? How - at all - is it compensated? Who can get away with a small contribution to the housework, and who cannot?

- How - through which mechanisms, and drawing in which voices - is intellectual labour parcelled out in the project? Who is included in, or allowed to partake of, conceptual and 'philosophical' discussion - and who is expected to simply collect data?

- Who writes and structures an interdisciplinary grant? Who brings the team together? Who does the tedious labour of working out everyone's costs? Who is responsible (or makes themselves responsible) for getting it in on time?

- What kinds of adjudications are made about what is and isn't an important part of the project's process - and through which mechanisms are those adjudications made explicit or not? For example, is spending time reflecting on how one organizes a workshop as valued as the substantive labour of the workshop itself?

-Who does public engagement work - and how, and why? Sometimes public engagement can be seen as low status work; but sometimes, too, it can be a moment for the assertion of seniority. How is this kind of work positioned and distributed in a given 
collaboration? Which kinds of audiences are deemed worthy of cultivating? How - and where - does this cultivation take place?

- Thinking through appropriate 'outlets' for publication can reveal all sorts of dynamics. On the one hand, the logic of impact factors and h-indices often determine where (and by whom) labour is placed in writing; one the other, the general orientation of a journal may make implicit decisions about whose contribution is and is not going to be valued (e.g. how does neuroscientific work get positioned in a decision to submit an interdisciplinary paper to a cultural theory journal?). How - and by whom - do such decisions get made within a collaboration?

- Interdisciplinary, co-authored work of course (usually) needs to find some mid-range voice in which to articulate itself. But dynamics of power can sometimes structure both the relative claim that different disciplinary registers have on that middle range, as well as the pernicious maintenance of the fiction of a 'transparent language' (in other words, that one's one language represents the neutral position). How are registers of appropriate voice generated within the project? What do those voices sound like - and what legacies do they drawn upon?

- Sometimes expertise is considered fungible, and sometimes it is not; sometimes it is regarded as easily understandable, and some it isn't; some expertise is seen not as expertise but merely as 'common sense'. Focusing on such positioning and understandings of different expertise can often be a salutary experience in interdisciplinary work.

- When papers are co-authored, how and when do particular conventions from different disciplines get pulled in? Does the team follow the multi-authored conventions of the natural sciences (and the stratification of contribution that it implies), or does it follow the lone-muse humanities model (and the occlusion of other voices that thus becomes inescapable)? If artists are part of the collaborating team, has anyone worked to rethink practices of creative production (in relation to curatorship)? 